\title{
Clinical evaluation of wheezy chest in children below 2 years of age in Hawler governorate
}

Received : 12/12/2010

Accepted: 28/5/2011

$\begin{array}{ccc}\text { Parween N. Ahmed * } & \text { Dlair AbdulKhalik Chalabi ** } & \text { Kawes O.Hamad Zangana ** } \\ \text { Abstract }\end{array}$

Background and objectives: Acute respiratory tract infection is a leading cause of childhood morbidity \& mortality in developing countries .respiratory distress with wheezing in infants is quite common \& presents substantial diagnostic problems. The aim is to determine the clinical characteristics of wheezy chest in children below 2 years of age in Raparin pediatric hospital in Hawler Governorate

Methods: a prospective study conducted between $1^{\text {st }}$ of January till $1^{\text {st }}$ of June 2007 in Rapreen hospital , three hundreds children of 1-24 months old admitted with respiratory distress $\&$ acute wheezing were recruited $\& 62$ children with no respiratory distress were also studied as control cases. Chest x-ray, total \& differential WBC counts were undertaken for all of them.

Results: of the 300 cases, 191 were due to bronchiolitis .thier age were between 1-6 months $(47.23 \%)$, male was the most common gender affected $(67.67 \%)$. Fever with temperature above $37.7 \mathrm{Co}$ indicate pneumonia (68.9\%) more likely rather than other 2 diseases (asthma ,bronchiloitis). One hundred percent of cases of asthma had history of previous attack of wheeze \& +ve family history of atopy.Among bronchopneumonia patients, $77 \%$ had opacity in chest X-ray(CXR) while $39.9 \%$ of bronchiolitis cases had normal CXR. In $84.8 \%$ of cases with bronchiolitis WBC count were normal with only $4.2 \%$ had lymphocytosis , while $11.5 \%$ of bronchopneumonia patients had leukocytosis with $24.6 \%$ of these cases had neutrophilia.

Conclusion: It can be concluded from this study that bronchiolitis ,bronchopneumonia \& asthma can be differentiated up to reasonable extent on the basis of clinical features supported by simple available investigations..

Keywords: Wheezy child ,Bronchiolitis ,Bronchopneumonia ,Asthma

\section{Introduction}

Respiratory distress with wheezing in infants is quite common \& presents substantial diagnostic problems ${ }^{1} ; 20 \%$ of children under 5 years wheeze at some time \& asthma is the commonest cause of wheezing. ${ }^{2}$ Bronchiolitis is usually caused by viral infection, most commonly respiratory syncytial virus (RSV). RSV infection are responsible for more than half of all cases of the illness $\&$ are most widespread in the winter \& early spring . There is no evidence of a bacterial cause for bronchiolitis. 3,4,5 Bronchopneumonia refers to inflam- mation of lung that is centered in the bronchioles \& lead to the production of mucopurulent exudates that obstructs some small airways ${ }^{4}$, viral infections are more common but bacterial infection are more severe ${ }^{5}$. Asthma is a chronic disease of reversible airway obstruction characterized by bronchial hyper responsiveness, inflammation \& mucus secretion. ${ }^{3,5,7}$ In bacterial infections such as pneumonia the fever is usually high while in bronchiolitis it is rarely above $38{ }^{0} \mathrm{C}^{2,8}$ Chest $\mathrm{x}$-ray findings like overinflated lung fields suggest likely diagnosis of asthma while hyperinfla-

*Erbil surgical cardiac center, Erbil, Iraq.

**Department of Pediatrics, College of Medicine, Hawler Medical University, Erbil, Iraq. 
tion with patchy infiltrates \& atelectasis suggest bronchiolitis \& lobar consolidation suggest bacterial pneumonia. WBC (White blood cells) count $>20000$ with neutrophilia suggest bacterial pneumonia ${ }^{8,9}$ while normal WBC \& differential count is the usual finding in bronchilitis. ${ }^{3}$

\section{Methods}

This prospective study was conducted among 300 children selected randomly of 1 - 24 months old of both sexes in pediatric teaching hospital presenting with respiratory distress \& chest wheezing during the period from $1^{\text {st }}$ of January $-1^{\text {st }}$ of June 2007. Cases of foreign body inhalation, congestive cardiac failure, congenital heart disease, and lobar pneumonia, congenital malformations of the airway, croup and pulmonary tuberculosis were excluded after detailed history \& clinical examination. A sample size of 300 was estimated to describe the clinical characteristics of wheezy child in children by detailed history \& physical examination. General examination \& respiratory system examination were performed. Corrected axillary temperature was taken for all patients at time of examination during $1^{\text {st }} 24$ hours of admission \& temperature of $\geq 37.7{ }^{\circ} \mathrm{C}$ considered to be febrile ${ }^{\cdot 10}$. Erect chest X-ray (CXR), Total \& differential WBC including absolute neutrophil \& lymphocyte count were done for all cases. Sixty two control cases with no dyspnea \&with no evidence of infection were taken randamly from pediatric surgical unit preoperatively mostly for inguinal hernia. circumsion, undesended testis, hydrocele etc . Total \& differential count including absolute count \& chest x-ray were done for all cases. The data were collected \& entered into SPSS version 11.5; parametric tests were used for normally distributed \& non parametric tests for skewed data. $P$ value less than 0.05 considered significant. Many recruited cases were excluded after questionnaires were completed due to inadequate blood sample or parental refusal of take blood sample for their children.

\section{Results}

Most cases were initially diagnosed as bronchiolitis as shown in (Figure 1) All conditions were common in the first 6 months of life as shown in (Figure 2) \& most cases were male as in (Figure 3 ) all were statistically highly significant $(p=0.00)$. Difference in temperature readings were statistically significant $(p=0.00)$, High temperature $(\geq$ $37.7 \mathrm{Co}$ or $100 \mathrm{~F}$ ) found in $68.8 \%$ of pneumonia patients at time of examination in the hospital as shwon in (Figure 4) \& nearly all cases had history of cough as shwon in (Figure 5) ( $p=0.01$ ). Most patients with wheezy chest had another first degree relative with ARI as shwon in table.6 \&was statistically significant compared to control $(p=0.00)$. History of previous attack of wheeze \& positive family history of atopy in other family members of first degree found in $100 \%$ of cases of asthma as shown in (Figure 7) \& (Figure 8) which both are statistically significant (both $p=0.00$ ). As shown in (Figure 9), the msot common radiological finding among patients with pneumonia is opacity in CXR while most patients with asthma \& bronchiolitis have normal CXR. Most of patients have normal WBC count as shown in (Figure 10), with normal differential count of neutrophil, lymphocyte ,eosinophil in most patients but increase in the frequency of patients with neutophilia in bronchopneumonia cases ,\& increase in frequency of patients with eosinophilia in asthma cases as shown in (Figure 1). 


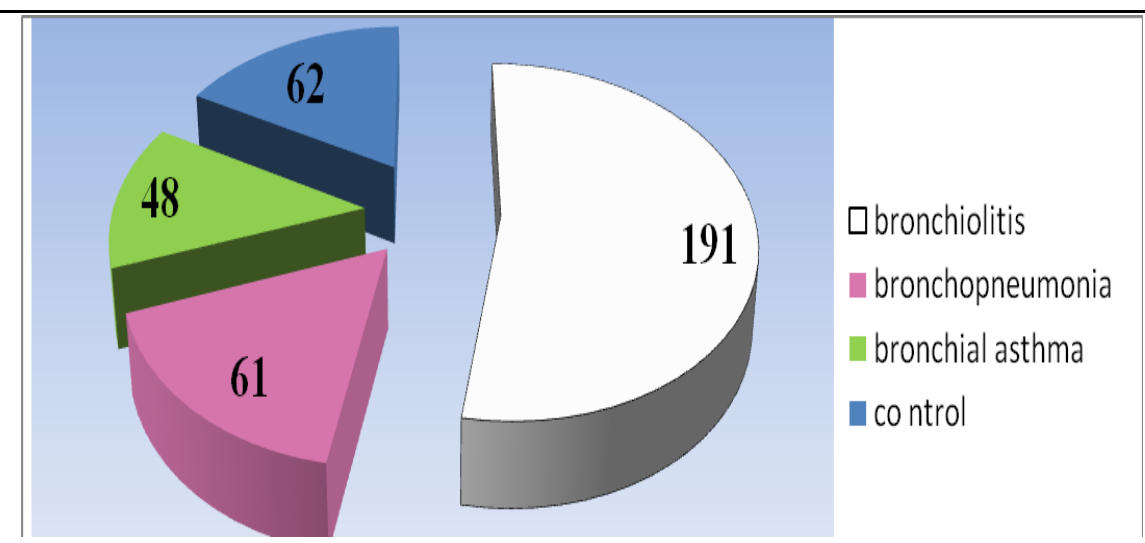

Figure 1: Provisional diagnosis of wheezy child.

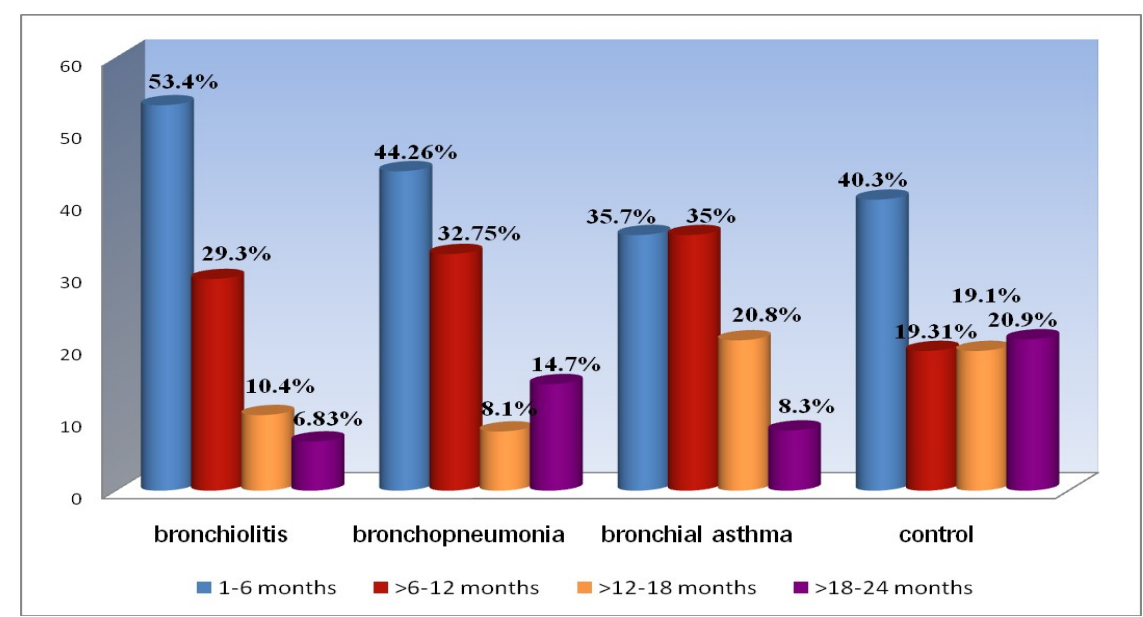

Figure 2: Age distribution of wheezy child \& control cases

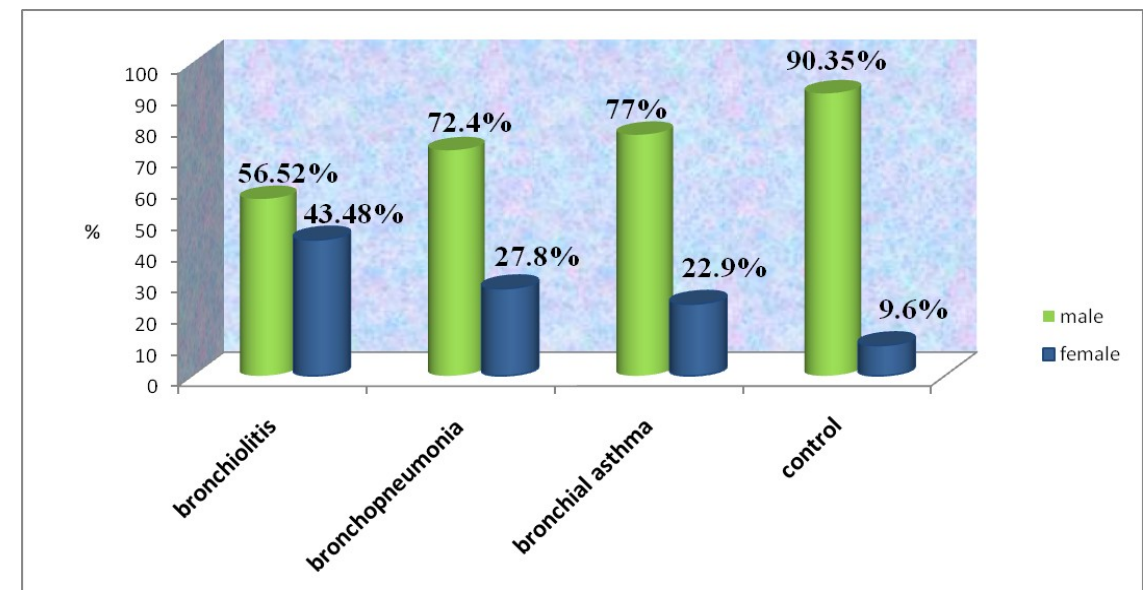

Figure 3: Gender distribution of wheezy child \& control cases 


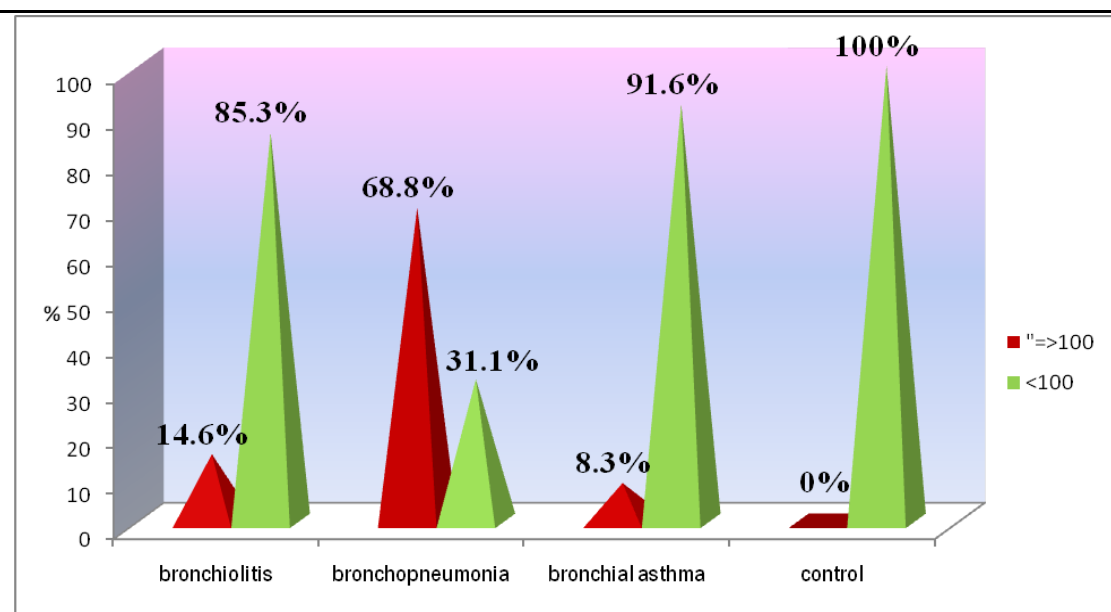

Figure.4 : temperature at time of examniation of wheezy child \& control cases

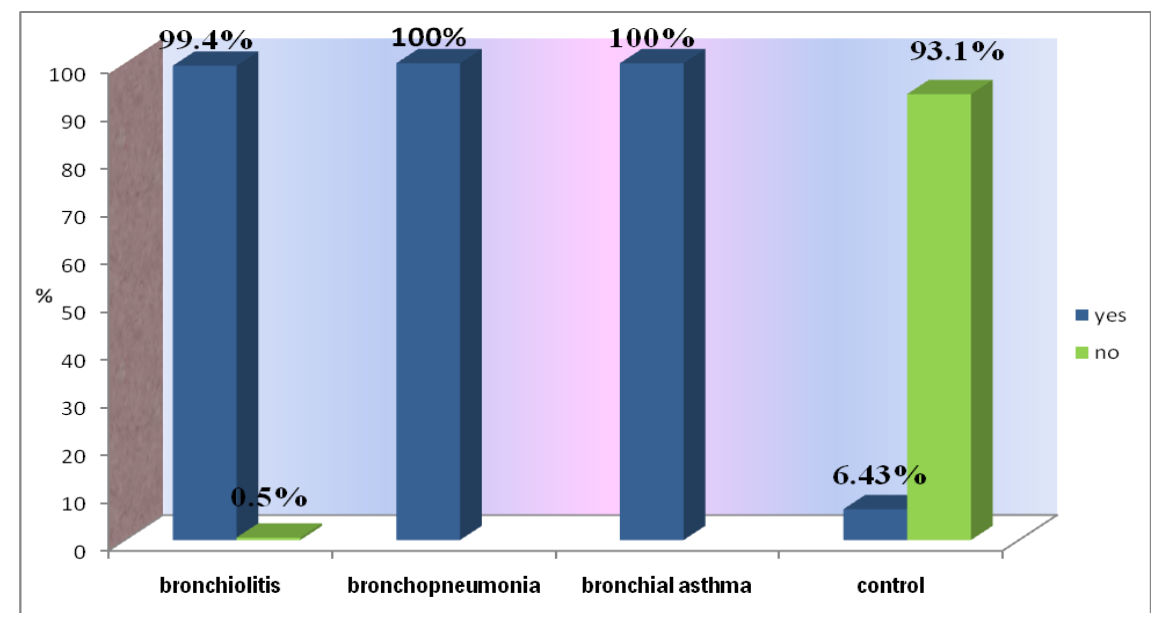

Figure.5: Cough in wheezy child \& control cases

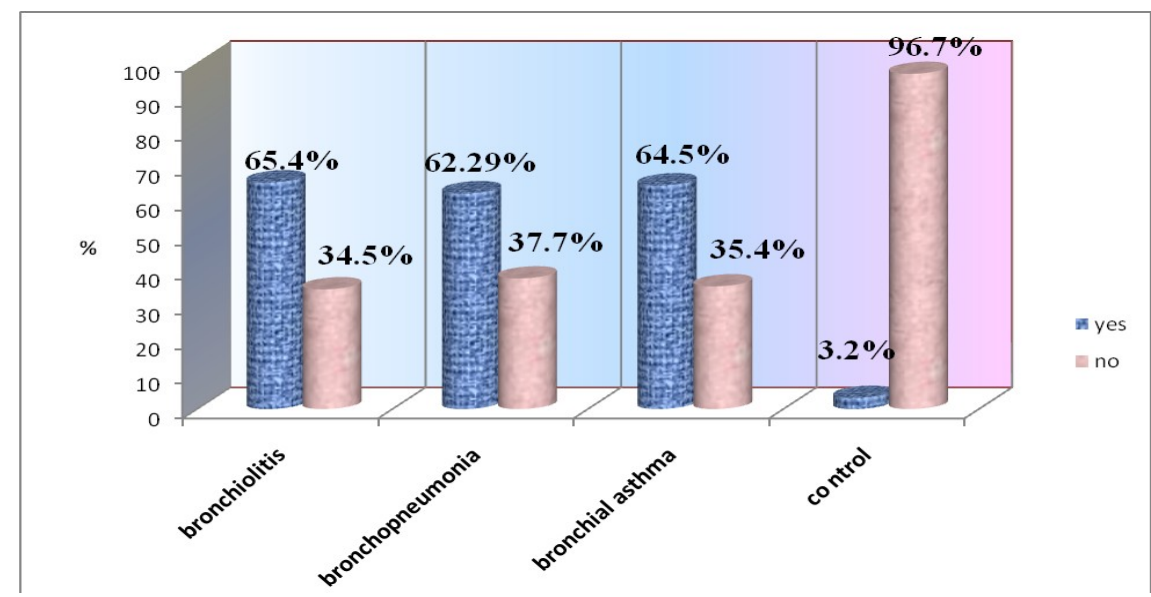

Figure 6: Family history of ARI in other family members 


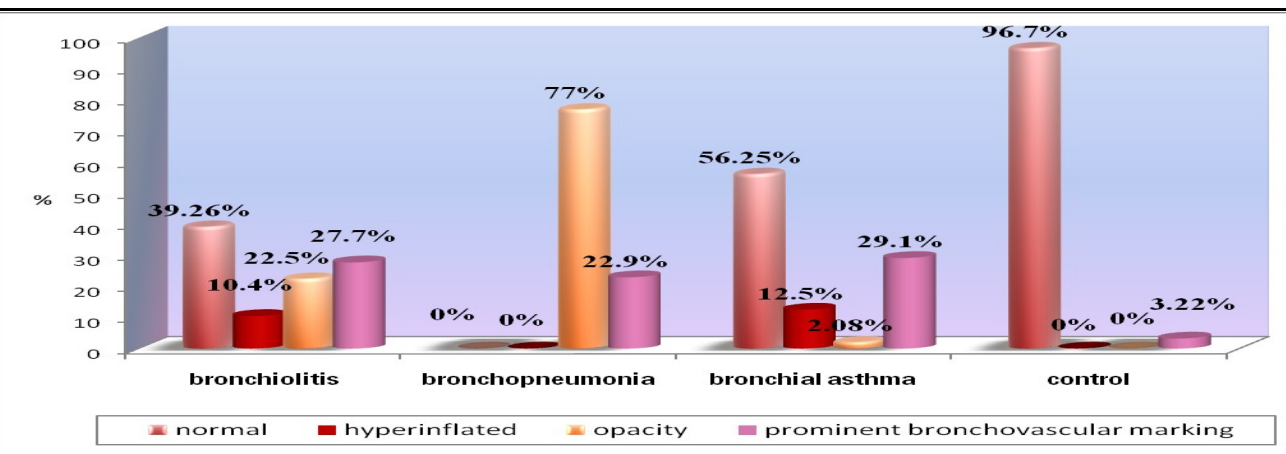

Figure 7: Previous history of wheeze in wheezy child

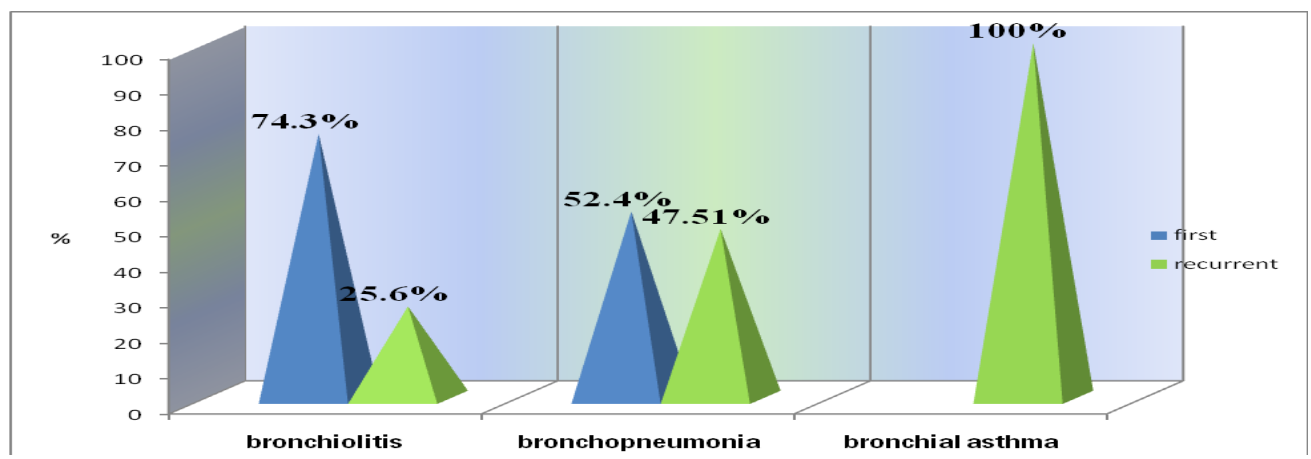

Figure 8: Family history of atopy in whhezy child \& control cases

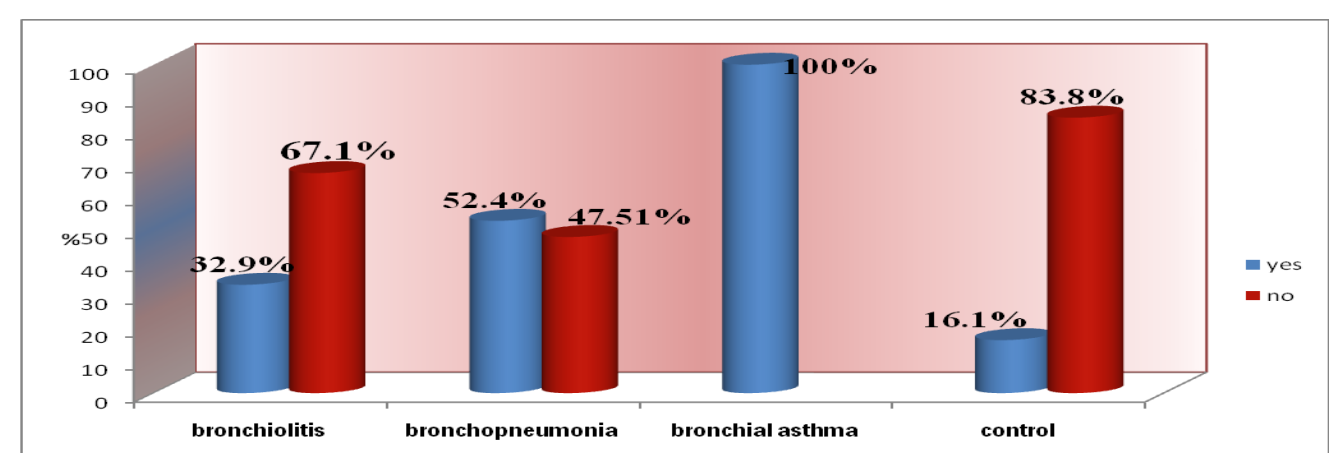

Figure 9: X-ray findings in Wheezy child \& control cases

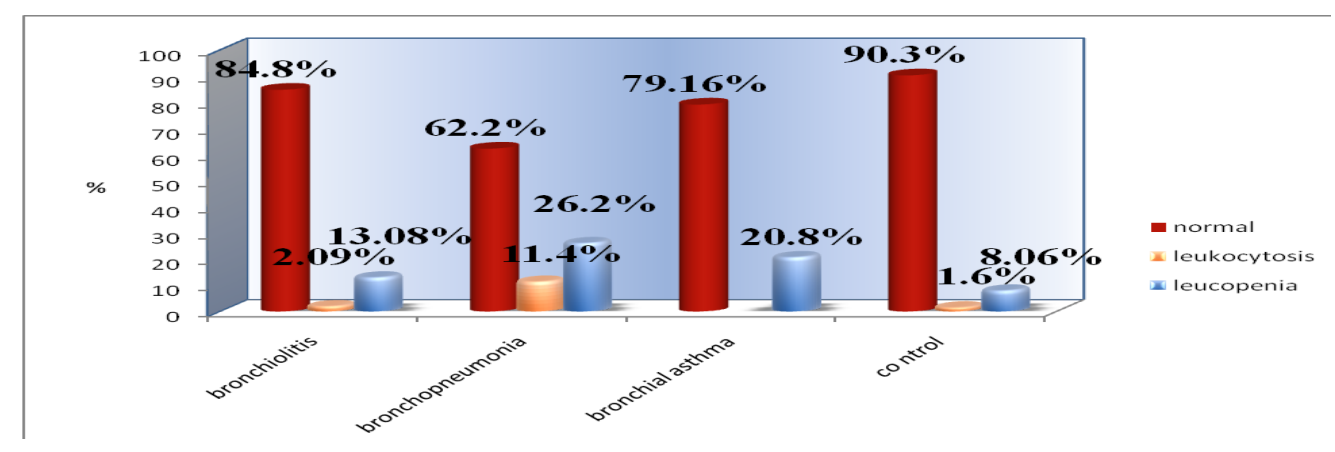

Figure 10 : Total WBC count in wheezy child \& control cases 
Table 1: differential WBC of wheezy child \& control cases.

\begin{tabular}{|c|c|c|c|c|c|c|}
\hline & & Bronchiolitis & Pneumonia & Asthma & Control & Total \\
\hline \multicolumn{7}{|c|}{ Absolute lymphocyte count } \\
\hline \multirow[t]{2}{*}{ Normal } & Count & 157 & 39 & 33 & 53 & 282 \\
\hline & $\%$ & $82.19 \%$ & $63.93 \%$ & $68.75 \%$ & $85.48 \%$ & $77.9 \%$ \\
\hline \multirow[t]{2}{*}{ Lymphocytosis } & Count & 8 & 3 & 2 & 1 & 14 \\
\hline & $\%$ & $4.19 \%$ & $4.91 \%$ & $4.17 \%$ & $1.61 \%$ & $3.86 \%$ \\
\hline \multirow[t]{2}{*}{ Lymphopenia } & Count & 26 & 19 & 13 & 8 & 66 \\
\hline & $\%$ & $13.61 \%$ & $31.14 \%$ & $27.08 \%$ & $12.9 \%$ & $18.23 \%$ \\
\hline \multirow[t]{2}{*}{ Total } & Count & 191 & 61 & 48 & 62 & 362 \\
\hline & $\%$ & $100 \%$ & $100 \%$ & $100 \%$ & $100 \%$ & $100 \%$ \\
\hline \multicolumn{7}{|c|}{ Absolute neutrophil Count } \\
\hline \multirow[t]{2}{*}{ Normal } & Count & 174 & 40 & 44 & 53 & 311 \\
\hline & $\%$ & $91.09 \%$ & $65.57 \%$ & $91.66 \%$ & $85.48 \%$ & $85.91 \%$ \\
\hline \multirow[t]{2}{*}{ Neutrophilia } & Count & 5 & 15 & 0 & 0 & 20 \\
\hline & $\%$ & $2.62 \%$ & $24.57 \%$ & & & $5.52 \%$ \\
\hline \multirow[t]{2}{*}{ Neutropenia } & Count & 12 & 6 & 4 & 9 & 31 \\
\hline & $\%$ & $6.28 \%$ & $9.83 \%$ & $8.33 \%$ & $14.51 \%$ & $8.56 \%$ \\
\hline \multirow[t]{2}{*}{ Total } & Count & 191 & 61 & 48 & 62 & 362 \\
\hline & $\%$ & $100 \%$ & $100 \%$ & $100 \%$ & $100 \%$ & $100 \%$ \\
\hline \multicolumn{7}{|c|}{ Absolute eosinophil Count } \\
\hline \multirow[t]{2}{*}{ Normal } & Count & 180 & 59 & 41 & 54 & 334 \\
\hline & $\%$ & $94.24 \%$ & $96.72 \%$ & $85.41 \%$ & $87.09 \%$ & $92.26 \%$ \\
\hline \multirow[t]{2}{*}{ Eosinophilia } & Count & 11 & 2 & 7 & 8 & 28 \\
\hline & $\%$ & $5.75 \%$ & $3.27 \%$ & $14.58 \%$ & $12.9 \%$ & $7.73 \%$ \\
\hline \multirow[t]{2}{*}{ Total } & Count & 191 & 61 & 48 & 62 & 362 \\
\hline & $\%$ & $100 \%$ & $100 \%$ & $100 \%$ & $100 \%$ & $100 \%$ \\
\hline
\end{tabular}

Note: \% taken within the initial provisional diagnosis

\section{DISCUSSION:}

The study group were 1 month to 24 months old \& bronchiolitis constitute $53.4 \%$ \& most were between 1-6 months ,this agrees with other studies 3,4,7,11 where peak incidence of bronchiolitis were betw- een 3-6 months of age. In this study, $85.3 \%$ of bronchiolitis cases had no fever while $68.9 \%$ of bronchopneumonia cases had fever \& this result agrees with another study ${ }^{1}$ which shows $88 \%$ of bronchopneumonia patients had fever \& $67.7 \%$ of bronchilitis patients had no fever.A history of 
cough was more common with $99.5 \%$ in bronchiolitis \& $100 \%$ in bronchopneumonia \& bronchial asthma, this nearly confined to a study done in Erbil where cough found in $100 \%$ of patients with bronchiolitis, bronchopneumonia \& bronchial asthma.\& this confirms that cough is major symptom for children with wheezy chest. ${ }^{12}$ Most cases of bronchiolitis had history of URTI in other family members. older family members are a common source of infection but may experience only minor respiratory symptoms ${ }^{5}$. Recurrent attacks or past history of similar wheezing episodes was observed in $100 \%$ infants who had bronchial asthma which is similar to other studies. ${ }^{1,13}$ All cases of bronchial asthma had family history of atopy in this study. Family history of asthma or other allergic disorders was observed to be an important criteria for diagnosis of bronchial asthma as shown by Naresh et al. ${ }^{1}$ Chest X-ray findings of bronchiolitis $(39.3 \%$ normal, $10.5 \%$ hyperinflation, $22.5 \%$ opacity \& $27.7 \%$ prominent bronchovascular markings) fit with another study ${ }^{1}$ were $35.3 \%, 44.2 \%$ \& $20.5 \%$ had opacity ,hyper inflation \& prominent bronchovascular markings respectively. In patients with broncho-pneumonia ( $77 \%$ opacity , $23 \%$ prominent bronchovascular markings ), this result is lower than a study ${ }^{1}$ showed $100 \%$ opacity. In bronchial asthma ( $56.3 \%$ normal, $12.5 \%$ hyperinflation, $2.1 \%$ opacity $\& 29.2 \%$ prominent bronchovascular markings) which also confined with a study ${ }^{1}$ showed $25 \%$ hyperinflation , $31.2 \%$ prominent bronchovascular markings \& $43.8 \%$ had normal.Most cases of bronchiolitis had normal total WBC count which was in agreement with Goodman ${ }^{2}$ in which white blood count were normal while $11.5 \%$ of bronchopneumonia\& no one of bronchial asthma had leukocytosis. Only few cases of bronchiolitis ,asthma \& pneumonia had lymphocytosis which is also in agreement with Naresh et al ${ }^{1}$ who showed lymphocytosis only in $5.8 \%$ for bronchiolitis \& $0 \%$ for broncho-pneumonia \& bronchial asthma .Relatively, bronchopneumonia more likely than asthma \& bronchiolitis to have neutrophilia, these results coincide with Korppi $M$ et $\mathrm{al}^{14} \&$ Naresh et al $^{1}$ regarding bronchiolitis \& bronchial asthma but not for bronchopneumonia (100\% had neutrophilia) compaired to our result $24.6 \%$. Eosinophilia present in only $14.6 \%$ of patients with asthma compared to $68.7 \%$ showed in a study done in India ${ }^{1}$ at 2001.

\section{Conclusions:}

Presence of fever, neutrophilia \& opacities in the chest $X$ ray point to the diagnosis of bronchopneumonia while absence of fever with normal leukocyte count or lymphocytosis point towards bronchiolitis in young children with respiratory distress \& chest wheezing. Recurrent attacks with positive family history of bronchial asthma \& allergic disorders \& eosinophilia suggest diagnosis of bronchial asthma in young childrens with respiratory distress \& chest wheezing .

\section{References}

1.Naresh K,Narinder S ,Locham K. ,Rajinder G, Sarwal $D$.Clinical evaluation of acute respiratory distress \& chest wheezing in infants. Ind ped j . 2002; $39: 478-483$.

2.Carter E. Noisy Breathing. In: Field D, Isaacs D, Stroobant $\mathrm{J}$,editors. Tutorials in pediatric differential diagnosis. 2nd ed. Edinburgh. Churchill Livingstone2005.112-113.

3.Goodman D. inflammatory disorders of small airways .in: Berman R., Kliegman $M$, Jenson $B$,editors. Nelson Textbook of Pediatrics.17 ed. Philadelphia. Saunders; 2004.1415-1418.

4.Dawshen S., kidshealth online. infectious bronchiolitis.inc.: 2004 (accessed 2008 Jan) available from : http// kidshealth.org/parent/infectious/ bacterial/viral/bronchiolitis.html

5.Prince A. infectious diseases in: Berhman R. ,Kleigman $M$,editors. Nelson Essentials of pediatrics.5th edition.Philadelphia. Saunders.2006.445577

6.Eichiner J. ,Berman S. Bronchiolitis. In: Berman S.,editor. Pediatric Decision making. 4th edition. Philadelphia. Mosby; 2004. 748- 751.

7.Joseph E. Kids health online. Wheezing \& asthma in infants. Inc.: 2004 (accessed Jan 2008). Available from: http://kidshealth.org/ parent/medical/ asthma/wheezing asthma.html

8.Roberts K., Akintemi O ,Clemens C. bronchiolitis \& pneumonia. In: Roberts B. editor. Manual of clinical problems in paediatrics .5th edition. Philadelphia: Lippincott Williams\& Wilkins.2001.261-67.

9.Witcoff L. Pulmonology. in: Brown L., Miller L. Editors. Board Review Series / Paediatrics. Baltimore. Lippincott Williams \& Wilkins. 2006. 264-65. 
10.Barkin R. ,editor. Problem Oriented Pediatric Diagnosis. 2nd edition.Philadelphia .Lippincott Williams \& Wilkins. 2001. P 23.

11.Eriksson $M$, Bennet $R$, Rotzen-Ostlund $M$, von Sydow M, Wirgart B Z. Population-based rates of severe respiratory syncytial virus infection in children with and without risk factors, and outcome in a tertiary care setting. Acta Paediatr. 2002; 91: 593598

12.Alnajjar S. ,Alrabaty A., ALhatem I. chest X-ray in suspected pneumonia in pediatrics, clinicradiological study. Hawler :Hawler medical university. 2007

13.Sachdev H., Vasanthi B., Satyanarayna B., Puri R. Simple predictors to differentiate acute asthma from ARI in children: implications for refining case

14.14. Korppi M, Heiskanen-Kosma T, Leinonen M. White blood cells, C-reactive protein and erythrocyte sedimentation rate in pneumococcal pneumonia in children. Eur Respir J. 1997 May;10(5):11259. 